\title{
THE SPECIFIC GRAVITY OF BULL SPERMATOZOA FROM DIFFERENT PARTS OF THE REPRODUCTIVE TRACT*
}

\author{
U. LAVON, R. VOLCANI, D. AMIR AND D. DANON $\dagger$ \\ Department of Animal Science, Volcani Institute of Agricultural Research, Rehovot, \\ Israel, and †The Weizmann Institute of Science, Rehovot, Israel
}

(Received 28th Fuly 1966)

There are a few reports on the changes in specific gravity (s.G.) during maturation and ageing of spermatozoa. Lindahl \& Kihlström (1952) found the s.G. of bull spermatozoa to range between 1.240 and 1.334. The s.G. decreased from 1.2867 to 1.2668 when three consecutive ejaculates were collected. Lindahl \& Thunqvist (1965) found a value of $1 \cdot 10$ to 1.12 for the s.G. of bull epididymal spermatozoa and a value of 1.21 to 1.33 for ejaculated spermatozoa. Assuming that spermatozoa from the epididymis and from later ejaculates are younger than those from the first ejaculates, they suggested that the s.G. of spermatozoa increases with maturation and ageing.

Spermatozoa were taken from different parts of the bull testis in order to ascertain whether their s.G. changes during maturation and ageing in the genital tract. Testes were removed immediately after slaughter from twelve healthy bulls, 12 to 14 months old, who had never been allowed to serve a cow.

Spermatozoa were collected from the mediastinum testis, caput epididymidis and cauda epididymidis. The sampling was carried out within $2 \mathrm{hr}$ of slaughtering.

The determination of the S.G. of spermatozoa was carried out according to the method of Danon \& Marikovsky (1964) for determination of the density distribution of a red cell population, which was adopted for determination of density distribution and s.G. of bull spermatozoa by Lavon, Volcani, Amir \& Danon (1966).

To prevent an alteration in the s.G. of the removed cells, which may be caused by the use of electrolyte solutions, the cells were drawn directly from the organ into capillaries of the type used in micro-haematocrit determinations. The set of capillaries, $32 \mathrm{~mm}$ long and $0.8 \mathrm{~mm}$ in diameter, were previously prepared by drawing into each capillary tube a $5 \mathrm{~mm}$ column of a non-watermiscible phthalate ester mixture of pre-determined s.G. After sealing in a

* Contribution from the National and University Institute of Agriculture, Rehovot, Israel. 1966 Series, No. 1045-E. 
bunsen flame, the capillaries were centrifuged at $12,000 \mathrm{~g}$ for $15 \mathrm{~min}$. Average s.G. of the cells from a particular organ was calculated for the twelve bulls with the equation previously used (Lavon et al., 1966).

TABLE 1

THE AVERAGE SPEGIFIC GRAVITY OF SPERMATOZOA FROM DIFFERENT PARTS OF THE TESTIS

\begin{tabular}{l|c|c}
\hline \multicolumn{1}{c|}{ Locus of collection } & No. of trials & Average s.G. \pm S.E. \\
\hline Mediastinum testis & 23 & $1 \cdot 0440 \pm 0.002$ \\
Caput epididymidis & 15 & $1 \cdot 0583 \pm 0.002$ \\
Cauda epididymidis & 23 & $1 \cdot 0817 \pm 0.002$ \\
\hline
\end{tabular}
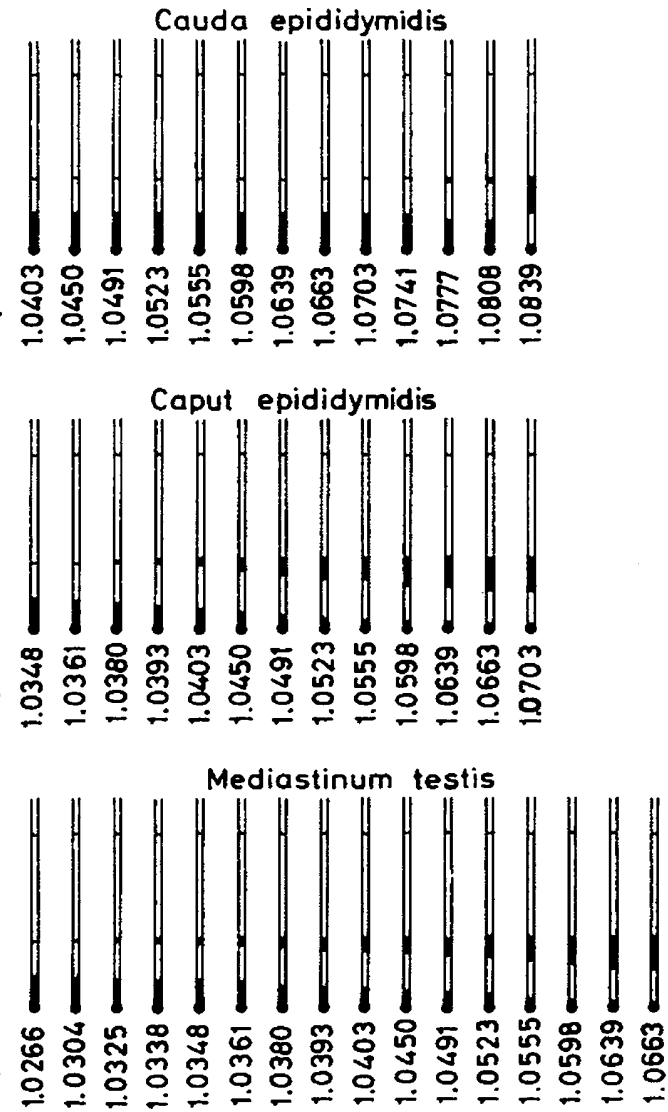

TexT-FIG. 1. Density distribution pattern of spermatozoa from the different parts of the testis in the set of micro-haematocrit tubes. s.G. = specific gravity of the phthalate ester mixture serving as separating fluid in the capillary tube.

The results obtained in this study are summarized in Table 1 , and the density distribution patterns of the spermatozoa from the different organs are shown in Text-fig. 1.

The present results demonstrate that the s.G. of spermatozoa increases 
during maturation and ageing while passing along the different parts of the genital tract of the bull, in agreement with Lindahl \& Kihlström (1952) and with Lindahl \& Thunqvist (1965). The values obtained for spermatozoa from the cauda epididymidis are close to those obtained previously for ejaculated spermatozoa (1.0696 to 1.0760 ) by Lavon et al. (1966). The differences between the values obtained in this study and those obtained by Lindahl \& Kihlström (1952) and Lindahl \& Thunqvist (1965) were due to the different methods used for the determination of the s.G. of spermatozoa, and were discussed previously (Lavon et al., 1966).

The density distribution patterns of the spermatozoa, as shown in Text-fig. 1, indicate that the specific gravity of spermatozoa in the mediastinum testis and in the caput epididymidis is spread over a wider range than in the cauda epididymidis. It is concluded that during maturation and ageing the spermatozoan population becomes more homogenous while its S.G. increases.

This study is part of a thesis to be submitted by the first author (U.L.) in partial fulfilment of the requirements for a Ph.D. degree from the Hebrew University of Jerusalem.

This research has been financed in part by a grant awarded by the United States Department of Agriculture under P.L. 480.

\section{REFERENCES}

Danon, D. \& Marixovsky, Y. (1964) Determination of density distribution of red cell population. 7. Lab. clin. Med. 64, 668.

Lavon, U., Volcani R., Amir, D. \& Danon, D. (1966) The specific gravity of bull spermatozoa and seminal plasma. 7. Reprod. Fert. 11, 447.

Lindaht, P. E. \& Kinlström, J. E. (1952) Alterations in specific gravity during the ripening of bull spermatozoa. f. Dairy Sci. 35, 393.

Lindahl, P. E. \& ThUnQVist, L. O. (1965) Specific gravity of epididymal and ejaculated bull spermaozoa and of their parts. Experientia, 21, 94. 